\title{
ANTAGONISMO DE TRICHODERMA SPP A FITOPATÓGENOS CAUSADORES DE PODRIDÃO DE RAIZ DE MANDIOCA EM ALAGOAS
}

\section{ARTIGO DE REVISÃO}

SILVA, Izael Oliveira ${ }^{1}$

AMORIM, Edna Peixoto da Rocha ${ }^{2}$

JUNIOR, Nelson Augusto Nascimento ${ }^{3}$

PEIXINHO, Georgia Souza ${ }^{4}$

CARNAÚBA, Juliana Paiva ${ }^{5}$

NETO, Vicente Ferreira de Araujo ${ }^{6}$

SILVA, Izael Oliveira. Et al. Antagonismo de Trichoderma spp a fitopatógenos causadores de podridão de raiz de mandioca em alagoas. Revista Científica

1 Doutorado em Proteção de Plantas, Mestre em Produção Vegetal Mestrado, Bacharelado e Licenciado em Ciências Biológicas.

${ }^{2}$ Doutorado em Agronomia (Agricultura). Mestrado em Fitopatologia. Especialização em Didática Para o Ensino Superior. Graduação em Agronomia.

3 Doutorado em Proteção de Plantas. Mestrado em Agronomia (Irrigação e Drenagem). Graduação em Agronomia.

${ }^{4}$ Mestrado em Horticultura Irrigada. Graduação em Agronomia.

${ }^{5}$ Doutorado em Fitopatologia. Mestrado em Agronomia (Produção Vegetal e Proteção de Plantas). Aperfeiçoamento em Aperfeiçoamento em Ciências Biológicas. Graduação em Agronomia.

${ }^{6}$ Graduando em Agronomia. 
Multidisciplinar Núcleo do Conhecimento. Ano 05, Ed. 06, Vol. 12, pp. 149-177. Junho de 2020. ISSN: 2448-0959, Link de acesso:

\section{RESUMO}

Vários são fitopatógenos que limitam a produção de mandioca (Manihot esculata Crants) sendo podridão das raízes a que casam a maior perda na cultura chegando a $70 \%$. Esta cultura é de elevado interesse para a região Nordeste do Brasil, proporcionando grandes prejuízos. As dificuldades no manejo tem direcionado a busca por alternativas, entre as quais, o biocontroladores vem apresentando resultados significativos. Esta revisão bibliográfica teve como objetivo reunir informações relativas à podridão da raiz da mandioca cv Rosinha, os principais fitopatógenos e as atividades antagônicas de Trichoderma no controle das doenças no estado de Alagoas. Foi realizado um levantamento bibliográfico nas bases de dados Scielo, Google Acadêmico, portal da Capes (teses e dissertações), periódicos e livros. Para obtenção de informações sobre: podridão radicular da mandioca de mesa, Trichoderma spp., como agente de biocontrole de fitopatógenos.

Palavras-Chave: Raiz tuberosa, controle biológico, fitopatologia.

\section{INTRODUÇÃO}

Devido a seu valor nutricional a Manihot esculenta Crantz se destaca no Brasil e no mundo com expressiva contribuição econômica e social devido a sua versatilidade, pois é usada tanto na alimentação animal quanto humana e amplamente utilizada na indústria. A cultura exerce um significativo suporte a população com baixo poder aquisitivo, pois além de ser fonte nutritiva é também gerador de renda na agricultura familiar (NOTARO et al. 2013).

No mundo o consumo da mandioca e seus derivados estão na sexta posição no ranking sendo a soja, trigo, arroz, milho e batata as culturas que ocupam as primeiras posições segundo dados da Fao (2012). O Brasil é o quarto produtor mundial, com uma safra estimada para 2016 de 25 milhões de toneladas (IBGE, 2015). 
De grande versatilidade, a cultura é totalmente aproveitada, não só a parte aérea (folhas e hastes) como também a raiz. As folhas têm seu aproveitamento na alimentação humana (suplemento) e animal (triturada). As hastes, na alimentação animal, sob a forma de silagens e fenos e ainda in natura. A raiz, na alimentação humana, animal e ainda pelas indústrias, principalmente de farinha, de féculas, plásticos biodegradáveis, produtos têxteis e de biocombustível (CONAB, 2013).

A cultura da mandioca enfrenta muitos desafios, entre os quais, destacam-se os problemas fitossanitários (NASCIMENTO JÚNIOR, 2015). Diversas doenças já foram relatadas na cultura, dentre elas, as podridões radiculares, cujos agentes podem ser Lasiodiplodia sp., Pythium sp., Rosellinia sp., Fusarium sp., Neoscytalidium lignicola, Phytophthora drechsleri Tucker entretanto, os três últimos fitopatógenos são os mais frequentemente envolvidos na podridão radicular no estado de Alagoas (Figura 1) e na maioria das regiões produtoras. Informações sobre as podridões das raízes de mandioca ainda são incipientes e são de suma importância para servir como ferramenta na tomada de decisão sobre qual a melhor estratégia a se utilizar (MASSOLA JR; BEDENDO, 2005; MUNIZ et al., 2006; NOTARO et al., 2013; SILVA, 2013; FUKUDA; OTSUBO, 2015).

Entre os microrganismos causadores de podridão de raiz de mandioca $P$. drechsleri e F. solani, são os mais importantes devido a abrangências e severidade causando perdas significativas na produção. Em solos adensados e acidificados a ocorrência de Fusarium sp., é mais frequente, e uma das características deste patógenos é causar dano na haste junto ao solo por infecção dos vasos xilemáticos e consequentemente interferir na circulação da seiva, assim ocasionando a podridão indireta da raiz em qualquer faze do desenvolvimento da planta. Ao contrário de Phytophthora, cujos sintomas provocados nas raízes são de coloração marrom e apodrecimento de consistência mole que exsudam um líquido com mau cheiro, já as podridões de Fusarium sp., sem distúrbios aparentes nos tecidos com sinais de desidratação e aparência mumificada de uma podridão seca (MOURA; SILVA, 1997; POLTRONIERI et al., 2001; SILVA; TEIXEIRAS, 2012). 
Como medidas protetivas e de controle da podridão radicular são utilizados o manejo físico e químico do solo, mas uso de variedades tolerantes associadas a práticas culturais como rotação de cultura e sistema de cultivo tem surtido positivamente. Nascimento Júnior (2015), destaca que é de fundamental importância o conhecimento das condições edafo-climáticas da região do cultivo e o uso de técnicas apropriadas que possam ser adotadas pelo agricultor, para ter um retorno econômico dentro de um sistema agrícola sustentável. O controle alternativo de fitopatógenos com antagonistas, principalmente com espécies de Trichoderma, já vem sendo estudado, devido ao interesse mundial de utilizar produtos menos agressivos ao ambiente (SOUSA et al., 2012; SILVA et al., 2014). Para Robbs (1992) e Barbosa; Meza (2009) a competição por alimentos e a antibiose, são os mecanismos mais frequentemente utilizados por algumas espécies de Trichoderma, sendo por isso considerado um excelente agente de biocontrole.

Diante do exposto, o objetivo do presente trabalho foi realizar uma revisão bibliográfica a respeito dos principais fitopatógenos e o potencial de antagonismo de Trichoderma envolvidos com a podridão radicular da mandioca, no estado de Alagoas.

\section{METODOLOGIA}

O presente estudo consiste em uma revisão da literatura, realizada entre dezembro de 2014 e março de 2016, no qual se realizou uma consulta a artigos científicos, selecionados por meio da busca no banco de dados do Google acadêmico, LILACS, MEDLINE, SciELO, portal da Capes (teses e dissertações), periódicos e livros. Dos inúmeros artigos relacionados 84 deles foram utilizados. Como descritores utilizamos: podridão radicular, controle biológico de fitopatógenos, fitossanidade. 


\section{REVISÃO DE LITERATURA}

\subsection{A CULTURA DA MANDIOCA}

A mandioca, uma cultura de grande interesse para o Nordeste brasileiro, notadamente para o Estado de Alagoas, é uma planta perene, arbustiva, pertencente à família das Euforbiáceas, rica em fécula, utilizada na alimentação humana e animal ou como matéria-prima para diversas indústrias (FRAIRE FILHO; BAHIA, 2015).

Nascimento Júnior (2015), enfatiza as vantagens desta cultura, devido a sua rusticidade, baixo custo, adaptação em relação ao clima, solo e suas características nutricionais que estão relacionadas à grande acumulo de amido em suas raízes, bem como de proteínas e aminoácidos nas folhas. É uma planta originária das regiões tropicais da América do Sul, mas que teve como lugares da sua domesticação o Sudeste da Ásia, a África e a América Tropical (NOTARO et al., 2013; SILVA, 2013; FRAIRE FILHO; BAHIA, 2015).

Em 2013, foram produzidas 281.718 .000 toneladas de mandioca em todo o mundo, sendo o Brasil o quarto produtor mundial com 23.977.757 toneladas, ficando atrás da Nigéria, Indonésia e Tailândia. As regiões norte e nordeste do Brasil possuem grande volume de produção e área cultivada está no sul, sudeste e centro-oeste, as de maior rendimento agrícola. O Estado do Pará é o maior produtor nacional de raiz de mandioca, seguido de Paraná, Maranhão e Bahia (IBGE, 2015).

Em Alagoas, as regiões que se destacam como produtoras de mandioca são o agreste, com 70\% da produção total do estado (Arapiraca, São Sebastião e Campo Alegre), a zona da mata e o litoral norte, sendo a primeira região, a que detém a maior quantidade de produtores, responsável por 13,36 t.ha-1 e 240,448 toneladas, ocupando a segunda colocação em produtividade se comparados aos outros estados do nordeste (CONAB 2013).

Notaro (2012) enfatizaram que essa cultura ainda é de agricultura familiar e se desenvolve de forma rudimentar, sendo que o principal meio de propagação é

Disponível em: https://www.nucleodoconhecimento.com.br/agronomia/antagonismo-de- 
vegetativa e ainda são cultivadas variedades de baixa qualidade genética. A sua utilidade esta associada ao teor de ácido cianídrico (HCN) presente nas folhas e raízes, que a classifica como mansa ou doce (<180 $\mathrm{mg} \mathrm{kg}^{-1}$ de $\mathrm{HCN}$ ), também conhecidas como macaxeira, utilizada para o consumo in natura; intermediárias (180 - $300 \mathrm{mg} \mathrm{kg-}^{-1}$ ) e amarga ou brava (>300 mg kg-1) essas duas últimas são utilizadas para ração animal, produção de fécula, farinha e biocombustível (OLIVEIRA et al., 2012).

A maior utilidade da mandioca está na indústria alimentícia, principalmente na produção de fécula destinada para o mercado de amido modificado, que além de atender a culinária regional em pães, tapiocas, beijus, bolo de goma e pé-de-moleque; é um dos produtos derivados da planta que mais emprega mão-de-obra e agrega um elevado valor no produto processado, segundo Nascimento Júnior (2015). Quanto à utilização para extração de produtos fermentados na indústria de biocombustível, a mandioca vem se mostrando uma boa alternativa na fabricação de etanol, pois apresentou um menor custo energético na produção, comparando a cana-de-açúcar e o milho, de acordo com Salla et al., (2010).

Segundo Alves (2006), a fenologia da mandioca pode variar de 6 a 24 meses de cultivo, mas comercialmente é 12 a 18 meses para o beneficiamento de farinha e fécula e entre 8 a 10 meses para as de mesa. Dentre as variedades plantadas em Alagoas, destaca-se a Rosinha, cujo ciclo varia entre 9 a 10 meses em sequeiro, podendo ser antecipado para 7 a 8 meses em condições de sistema irrigado. Essa variedade pode atingir três metros de altura, mantém o 'stand' de plantas ao final do cultivo com boa produção de ramas e produtividade em 21 t ha-1 (DINIZ et al., 2009).

Nascimento Júnior (2015), relata em seu trabalho que mesmo com a rusticidade da cultura é necessário está atento às condições adafo-climáticas, afirmando que a mandioca produz bem em solos férteis, com pH entre 5,5 a 7,0 com classe textural arenosa ou média e uma boa drenagem natural. A condição climática ideal está na faixa de temperatura entre $20^{\circ} \mathrm{C}$ e $27^{\circ} \mathrm{C}$, podendo se estabelecer em ambientes com temperaturas entre $16^{\circ} \mathrm{C}$ e $38^{\circ} \mathrm{C}$; com precipitação entre 1000 a $1500 \mathrm{~mm}$ ano- ${ }^{-1}$, em 
regiões semi-áridas entre 500 e 700 mm ano-1; altitudes de 600 a 800 metros acima do nível do mar e período de luz de 12 horas dia-1 (SILVA; ANDRADE, 2011; SILVA, 2013).

\subsection{DOENÇAS NA CULTURA DA MANDIOCA}

Vários fatores podem limitar a produção da mandioca, tais como, a ocorrência de insetos-praga e fitopatógenos causadores de doenças, prejudicando a qualidade e desenvolvimento da cultura no Brasil e no mundo. De acordo com Nascimento Júnior (2015), a mandioca é suscetível a diversos fitopatógenos e isto acarreta severas perdas econômicas na produção.

Dentre as doenças de importância destacam-se as causadoras de lesões foliares como mancha parda (Cercosporidium henningsii) mancha branca (Phaeoramularia manihotis), queima das folhas (Cercospora vicosae), mancha preta (C. manihobaea) e antracnose (Colletotrichum gloeosporioides f.sp. manihotis) que limitam os fotoassimilados (SILVA; ANDRADE, 2011; MORAIS et al., 2013; OLIVEIRA et al., 2013). E as podridões radiculares, causadas por fungos e oomicetos, tais como Lasiodiplodia sp., Pythium sp., Rosellinia sp., Fusarium sp., Neoscytalidium lignicola, Phytophthora drechsleri Tucker entretanto, os três últimos fitopatógenos são os mais frequentemente envolvidos na podridão radicular no estado de Alagoas (Figura 1) e na maioria das regiões produtoras. Informações sobre as podridões das raízes de mandioca ainda são incipientes e são de suma importância para servir como ferramenta na tomada de decisão sobre qual a melhor estratégia a se utilizar (MASSOLA JR; BEDENDO, 2005; MUNIZ et al., 2006; NOTARO et al., 2013; SILVA, 2013; FUKUDA; OTSUBO, 2015).

Notaro et al., (2013) e Silva (2013) alertam sobre os altos impactos socioeconômicos causados pela podridão radicular da mandioca nos Estados do Maranhão, Pará, Alagoas e Pernambuco, pois está provocando perdas significativas na produtividade, além tonar as áreas inviáveis para plantio ao longo dos ciclos da cultura. Segundo Nascimento Júnior (2015), sendo o Omyceto Phytophthora sp e o fungo Fusarium sp., 
são principais patógenos da cultura no Nordeste e causam perdas que variam de 30 e $70 \%$. O autor afirma ainda que em condições favoráveis a doença pode provocar $100 \%$ de perda.

Figura 1. Aspecto das colônias e estruturas reprodutivas dos isolados de fitopatógenos causadores de podridão em mandioca no Estado de Alagoas: Fusarium sp. (A1-A6), Neoscytalidium sp. (B1-B6) e Phytophthorasp. (C1-C6). Colônia de Fusarium sp. (A1); conídios (A2); célula conidiogênica (A3-A6). Colônia de Neoscytalidium sp. (B1); Conídios (B2-B6). Colônia de Phytophthora sp (C1); Esporângio (C2); Clamidósporos (C3 E C4); Esporângios (C5) e Esporângios em reprodução (C6).

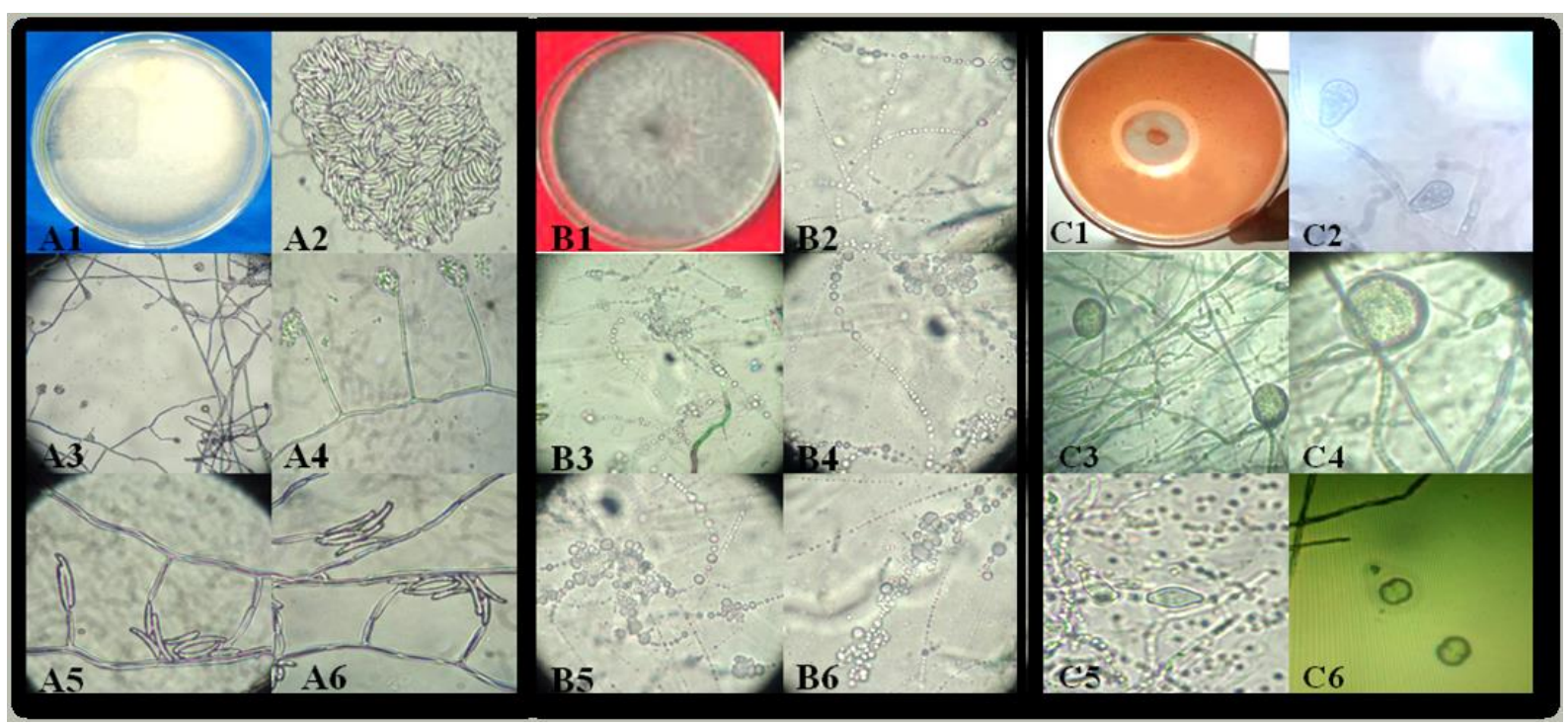

Fonte: SILVA e NASCIMENTO JÚNIOR (2016).

A podridão causada por Fusarium sp., ocorre em plantas jovens e adultas, com sintomas de murcha repentina e severo desfolhamento, que pode ser potencializado em áreas de solo argiloso e mal drenados (SILVA; TEXEIRA, 2012). Fato este já relatado por Gomes; Leal (2003), que ao trabalhar com mandioca nos Estados de Sergipe, Bahia e Alagoas, afirma que a podridão radicular é a doença mais limitante da cultura na região Nordeste, principalmente quando é implantada em áreas formadas por solo compactado.

Disponível em: https://www.nucleodoconhecimento.com.br/agronomia/antagonismo-de- 
Os fitopatógenos causadores da podridão apresentam sintomas distintos. Os autores relatam que normalmente, Phytophthora sp., ataca plantas adultas, causando podridão "mole" nas raízes, com odor muito forte, semelhantes ao de matéria orgânica em decomposição e coloração acinzentada. O surgimento dos sinais são mais frequentes e visíveis nas raízes, mas há relatos da existência de jovens apresentando sintomas na base das hastes de plantas recém- geminadas, causando murcha e morte total. Já no caso da podridão seca causada por Fusarium sp., raramente ocorrem danos diretos na raiz, mas o problema se acentua em qualquer fase do desenvolvimento da planta. (GOMES; LEAL, 2003; SILVA; TEXEIRA, 2012; NASCIMENTO JÚNIOR, 2015).

\subsection{O FITOPATÓGENO FUSARIUM}

O gênero Fusarium foi descrito em 1809, por Link. Os representantes deste gênero pertencem ao reino Fungi, filo Ascomycota, classes Eauscomycetes e Pyrenomycetes, ordem Hypocreales, apresentando 65 espécies, 55 variedades e 22 formas especiais, conforme Wollenweber; Reinking (1935) ${ }^{1}$ citado por Ventura (1999). Trata-se de um dos mais importantes fitopatógenos do mundo, com ampla distribuição geográfica, distribuídos no solo e em associação com plantas. Tendo espécies cosmopolitas e outras com ocorrência restrita a determinados ambientes (VENTURA, 1999). A maioria das espécies são sapróbios, mas existem representantes do complexo Fusarium que produzem micotoxinas que podem afetar a saúde humana e animal (URBEN et al. 2009). Seifert (2006); Querales (2010) relatam que o gênero Fusarium é um grupo complexo crescente em número de espécies e geram controvérsias taxonômicas para fitopatologistas.

Milanesi (2009), comenta que o Fusarium sp., pode ocorrer especialmente em locais de climas tropicais e subtropicais, e tem uma grande capacidade de sobreviver por longos períodos no solo fora de seus hospedeiros, através da formação de estruturas de resistências chamadas clamidósporos. Três grupos dentro do gênero são os exemplos mais específicos dessas mudanças, nomeados do grupo teleomorfo do 
complexo Gibberella fujikuroi (Sawada) Wollenw, o complexo Fusarium solani (Mart.) Sacc., e F. graminearum.

O gênero pode apresentar colônias de coloridas que variam de violeta, purpura escuro a laranja, mas a predominância é de colônia pálida de crescimento rápido, micélio aéreo e difuso (MARTINS, 2005). Puhalla (1981); Martins (2005); Agrios (2005), relatam que as estruturas dos conídios (micro e macro), morfologia, disposição, variedade de conidióforos e clamidósporos eram a base para identificação das espécies de Fusarium sp. Os taxonomistas clássicos descrevem a presença de microconídios unicelulares e uninucleados e macroconídios multicelulares frequentes com célula com apenas um núcleo como progenitor idêntico geneticamente. Os estágios sexuais de Fusarium são ascomicetos; o esporo sexual é o ascósporo. Os que alocados no gênero Nectria têm ascósporos bicelulares.

Cada célula do ascósporo bicelular é uninucleada e ambos os núcleos são geneticamente idênticos. Outros, como é o caso em Gibberella, formam ascósporos multicelulares. Martins (2005) menciona que as características morfológicas sofrem influência relacionada ao ambiente e a nutrição, desta forma os meios de cultura são utilizados para selecionar microrganismos e agrupá-los, tomando como base as necessidades nutricionais que são disponibilizadas no meio de cultura em condições padronizadas para identifica-los. Devido a esta plasticidade e variações de características fenotípicas encontradas neste fungo, a taxonomia baseada somente em conceitos morfológicos não é confiável. (MARTINS, 2005; URBENS et al., 2009; QUERALES, 2010).

A identificação da espécie de Fusarium é um dos primeiros passos para seu estudo. Tradicionalmente tem sido realizado com base na morfologia, desde a publicação do tratado do gênero "Die Fusarien", em 1935 por Wollenweber; Reinking ${ }^{1}$. Outros sistemas foram propostos, mas não resolveram o problema da identificação das espécies. As ferramentas para identificação foram incrementadas e incluem a utilização de microscopia ótica e eletrônica, meios seletivos e diferenciais, comparações enzimáticas, metabólitos secundários, bem como, o uso de tecnologias 
imunológicas e moleculares (LEAL-BERTIOLI, 1998; MARTINS 2005). O'Donnell et al., (2000); Summerell et al., (2003); Ottoni, (2008); comentam que com o advento das ferramentas moleculares a identificação de Fusarium esta baseada na morfologia, biologia e característica da espécie, baseado na compatibilidade sexual, filogenia e na sequências de regiões genômicas.

Há décadas, a identificação clássica usa a características morfológicas como base, mas tem gerado controversa, pois diversos taxonomistas e fitopatologistas acham necessário a utilização de outros modelos para separar as espécies, já outros, acreditam que esses modelos afetam a taxonomia do gênero. Vale salientar que prática na diagnose de agentes causais de doenças em plantasse a adoção dos modelos genéticos estão mais adaptados para os estudos realizados por micologistas. Não obstante, estas mudanças são pertinentes, dado que em um gênero possa existir espécies muito próximas e isto pode levar a uma diagnose errada com importantes consequências práticas (QUERALES, 2010).

De acordo com Notaro et al. (2013), Fusarium solani Math (Sacc) é a espécie que prevalente causa podridão radicular na mandioca cv branquinha no Estado de Pernambuco. Esta espécie produz, em meio de cultura, micélio aéreo, com coloração que varia do branco ao creme, tornando-se marrom-azulado quando esporodóquios estão presentes. Produz três tipos de esporos assexuados: os macroconídios em forma de foice, com dimensões aproximadas de 15-35 x 4-7 $\mu \mathrm{m}$ com 3-5 septos; os microconídios, que possuem ou não septo, medem cerca de $5-10 \times 1-3 \mu \mathrm{m}$ e os clamidósporos, que são hialinos, globosos, lisos a áspero, medindo de 6-10 $\mu \mathrm{m}$.

O estado sexual do fungo é Nectria haematococca (Ascomycete). Este fungo sobrevive em restos culturais, solo, tubérculos e sementes infectadas, podendo persistir durante vários anos. As condições ideais para o seu estabelecimento são as temperaturas que variam de 15 a $25^{\circ} \mathrm{C}$, umidade de 50 a $75 \%$, ocorrência de ferimentos, plantios em solos contaminados e armazenamento inadequado. Ferimentos no sistema radicular, principalmente os ocasionados por nematoides, facilitam a penetração do fungo nas raízes dos hospedeiros. 


\subsection{CONTROLE DA DOENÇA}

Por ser um patógeno veiculado pelo solo, sua eliminação, após a instalação na área de plantio se torna uma tarefa muito difícil e medidas de controle químico praticamente inexistem, exceto aquelas preventivas, como o uso de tratamento de sementes ou outros materiais de propagação (LAZAROTTO et al., 2012). O Controle cultural, baseado na prevenção de ferimentos durante a colheita e o armazenamento, o uso de sementes sadias e substrato livre do patógeno, utilizado uma única vez, a aplicação equilibrada dos nutrientes, eficiência na irrigação, bem como de variedades que apresentem características de resistência e o tratamento das estacas (maniva) e do substrato com fungicida para o semeio quando infectado, podem minimizar as perdas de produção.

Como medida de controle o que mais se mostrou eficiente baseado nas pesquisas realizadas no Nordeste pela Embrapa Mandioca e Fruticultura e Empresa de Desenvolvimento Agropecuária (EMAGRO), foi o uso de variedade tolerante (Osso Duro, Cedinha, Bibiana, clone 148/02, Aramaris e Kiriris), associado à rotação de cultura e sistema de plantio, que reduziram a podridão em cerca de 80\% (GOMES; LEAL, 2003; BETTIOL, 2009; LOBO JÚNIOR et al., 2009; LAZAROTTO et al., 2012).

Para o controle de Fusarium sp., o produto químico difenolconazol e thiram, no tratamento de solo e de sementes, são os mais recomendados devido à eficiência apresentada. No entanto, o controle químico se tornou constante e com o uso indiscriminado advieram problemas ecológicos, pois estes provocam alterações no ambiente favorecendo fitopatógenos com resistência devido à pressão seletiva, surgimento de surtos secundários, redução da população de microrganismos benéficos, devido ao depósito de resido que se acumula no solo, na água e nos alimentos tornando-os nocivos, com efeito deletério a animais e humanos (BIZI, 2015).

De uma maneira geral, os custos elevados da prática do controle químico, associado ao surgimento de resistência aos produtos comumente empregados, bem como a proibição do brometo de metila, torna essencial o desenvolvimento de técnicas 
alternativas de controle (BETTIOL, 2009; LOBO JÚNIOR et al., 2009; LAZAROTTO et al., 2012). Já para o biológico a indução de resistência de plantas é alternativa promissora, pois utiliza extratos naturais com propriedades microbianas e/ou indutoras (MORAES, 1992; STANGARLIN et al., 2008).

\subsection{BIOCONTROLE DE FITOPATÓGENOS}

A tentativa de reduzir as ações deletérias de um patógeno ou do inoculo tem sido uma constante na agricultura, e a substituição de agroquímicos por produtos naturais com atividade de supressão ou de controle tem sido uma das alternativas viáveis, pois o resíduo deixado é mais rapidamente assimilado e decomposto pelo ambiente devido a sua baixa persistência (SOUZA, 2013; BIZI, 2015).

Ethur, (2006) e Dianese, (2007); relatam a importância das pesquisas na área de controle biológico, tais como a introdução de organismos antagônicos em ambientes em que o patógeno esteja causando danos. Cancela (2015), afirma que a dinâmica da ação do controle biológico ocorre de forma natural e consiste na regulação do número de plantas e animais por inimigos naturais. Esta estratégia é parte fundamental do equilíbrio da natureza e como o controle químico apresenta vantagens e desvantagens. Entre as vantagens está o fato de ser uma medida atóxica, não provocar desequilíbrio, não possuir contraindicações, propiciar um extenso e eficiente controle quando não existe um controle químico, pois será necessário mais tecnologia devido ao seu efeito lento, de difícil aquisição e nem sempre pode ser aplicado em qualquer época do ano.

Manter o equilíbrio no Agroecossistema é uma prática do controle biológico de modo que o patosistema não cause danos significativos na ação biocontroladora dos organismos não patogênicos do sistema. Os autores relatam ainda que doença é mais que uma relação de interação de patógeno/hospedeiro, pois a influência do ambiente e também de uma diversidade de organismo não patogênicos repousa no sítio de infecção podem limitar ou aumentar a agressividade do patógeno, ou resistência do 
hospedeiro. Desta forma patógena, hospedeira e antagonista interagem entre si nos componentes do controle biológico (BIZI, 2015; CANCELA 2015).

Um fator limitante para o uso de produtos biológico é a disponibilidade no mercado para esta modalidade de controle. Outro problema é que muitos produtos naturais não estão devidamente registrados para uso em escala comercial (SILVA et al., 2008). A presença do fitopatógeno interfere na homeostase da planta, mas também pode atuar acionando mecanismos de defesa e/ou ativando genes que conferem resistência da planta hospedeira (AGRIOS, 2005). Michereff et al., (1993), afirmam que o patógeno possui atividades determinantes que envolvem crescimento, infectividade, agressividade, virulência e outras atribuições do patógeno ou processos, que determinam a infecção, desenvolvimento dos sintomas e reprodução. A interação entre antagonista, hospedeiro e patógeno não ocorre de maneira particular, mas mutuamente.

Diversos autores já descreveram capacidade que os biocontraladores têm de interagir e interferir no desenvolvimento do fitopatógeno por mecanismos de ação como competição por espaço e nutrientes a antibiose, micoparasitísmo ou hiperparasitísmo, predação, indução de resistência, aumentando assim vantagem competitiva no ambiente. Estes mecanismos variam de espécie para espécie e, também, de linhagem para linhagem dentro da mesma espécie, de acordo com a interação hospedeiroparasita. (CARVALHO, 2006; BETTIOL; MORANDI, 2009; BRITO et al., 2010; ZUCCHI, 2010; DIAS, 2011; MACHADO et al., 2012; BIZI, 2015; CANCELA, 2015; FIPKE, et al., 2015).

Muitos microrganismos têm apresentado elevado potencial biocontrolador e o gênero Trichoderma Pers. tem sido usado em vários estudos. T. hamatum (Bonord.) Bainier, T. viride Pers., T. aureoviride Rifai, T. harzianum Rifai, T. koningii Oudem, T. pseudokoningii Rifai e T. longibrachiatum Rifai são os mais citados (BETTIOL; GHINI, 2005). Ezziyyani et al., (2007) relatam que a frequência de Trichoderma spp., é devido a sua versatilidade seja por competição, hiperparasitismo e antibiose a fitopatógenos como Phytophthora, Fusarium e Neoscytalidium. Remuska \& Pria (2007) avaliando o 
efeito antagônico de Trichoderma spp., no controle do crescimento micelial de fungos fitopatogênicos observou que este exerceu antagonismo sobre alguns fitopatógenos radiculares, tais como Sclerotium rolfsii, Pythium aphanidermatum e Fusarium solani, sendo este último gênero descrito como um dos principais fitopatógenos associados à podridão da raiz da mandioca no estado de Pernambuco.

Hoffmann et al., (2015) relatam que tiveram $80 \%$ de controle de Fusarium sp., utilizando isolados de Trichoderma spp. Da Silva et al., (2011); Pereira (2013) comprovaram em seus trabalhos um grande nível de inibição de crescimento micelial de F. solani por espécies de Trichoderma spp. Souza et al., (2015) também tiveram resultados promissores com Fusarium sp., e Bipolaris sp., usando o mesmo biocontrolador. Outros trabalhos realizados por Bomfim et al., (2010); Dias (2011); Lazarotto et al., (2012); Santos et al., (2012); Marques et al., (2014), obtiveram resultados promissores apresentando de bom a ótimo desempenho, no que diz respeito a inibição do crescimento micelial de fitopatógenos por eles testados.

\subsection{ESTRATÉGIAS DE BIOCONTROLE DE TRICHODERMA}

O gênero Trichoderma, pertencente ao Reino Fungi, filo Ascomycota, classes Eauscomycetes e Pyrenomycetes, ordem Hypocreales, família Hypocreaceae, gênero Hypocrea (teleomorfo). Este fungo apresenta grande potencial antagônico e frequentemente é associado a solos supressivos. (MELO, 1991). De acordo com Harman et al. (2004); Harman (2005), seu uso pode oferecer outras vantagens: decomposição de matéria orgânica, competição com uma microflora deletéria através da colonização da rizosfera, produção de antibiose e indução de resistência.

Espécies de Trichoderma já foram documentadas para o controle de vários patógenos, tais como Rhizoctonia solani Kühn, Sclerotium rolfsii Sacc., Sclerotina sclerotiorum (Lib.) de Bary, Fusarium spp. e Pythium spp. (MELO; AZEVEDO, 1998). Inúmeras espécies de Trichoderma, incluindo T. harzianum Hifai, apresentaram uma elevada taxa de parasitismos e atividade antagônica para os fitopatógenos, tais como 
S. rolfsii, S. minor e $S$. sclerotiorum, $R$. solani e Pyricularia grisea Sacc. (ROLLAN et al., 1999; RONDÓN et al., 2007).

De acordo com Dos Santos (2010), o isolado de T. harzianum apresentaram antagonismo in vitro sobre o fungo $S$. rolfsii; sendo capaz de hiperparasitar as hifas do patógeno e competir por espaço e nutriente. Silva et al. (2013), trabalhando com isolados de Trichodema spp., como agente de controle biológico de S. lignicola, observaram que inicialmente o isolado de Neoscytalidium sp. mostrou-se bastante promissor quando confrontado com Trichoderma spp., porém ao se encontrarem na placa de Petri, o Trichoderma spp., sobrepôs a colônia do patógeno. Ao observar a região onde ouve a sobreposição do antagonista ao fitopatógenos foi possível notar uma degradação das hifas do patógeno por ação enzimática visto que se distinguia com precisão apenas esporos e hifas do antagonista.

Para Robbs (1992) e Barbosa; Meza (2009) a competição por alimentos e a antibiose, são os mecanismos mais frequentemente utilizados por agentes de biocontrole, uma vez que a reprodução e a colonização rápida são atributos de organismos que usam os recursos disponíveis com maior eficiência e rapidez, garantindo a sua sobrevivência. De acordo com Ethur (2006), a competição é uma das principais estratégias dos isolados de Trichoderma sp., por este fato são utilizados como biocontroladores.

A secreção de substâncias orgânicas antibióticas (antibiose), produzidas por microrganismos, que mesmo em baixa concentração interfiram nas atividades metabólicas, na inibição ou paralisação do crescimento e esporulação, redução na germinação de esporos, além de distorções na hifa e endólise, quer seja especifica, quer seja de amplo aspecto de ação, são importantes artifícios para eficiência de organismos antagonistas (LOBO JUNIOR; ABREU, 2000; BOMFIM, 2007; SOUZA, 2013). Segundo Claydon et al., (1987), antibióticos são produtos do metabolismo secundário de seus produtores, e podem ser mais importantes na inibição de outros organismos do que a competição por nutrientes. A antibiose também foi relatada por diversos pesquisadores como um dos mecanismos de ação de espécies de 
Trichoderma (BETTIOL, 1991; DIAS, 2011; CARVALHO FILHO, 2013). A gliotoxina, viridina e trichodermina, são algumas das substâncias produzidas por espécies de Trichoderma capazes de inibir o desenvolvimento de outros fungos (Amorim et al., 2011). Ethur (2006) relatou que a gliotoxina foi responsável pela inibição da germinação de esporângios e do crescimento micelial de Pythium ultimum.

Segundo Bomfim et al., (2010) e Souza (2013), o biocontrolador será bem-sucedido se for capaz de degradar a parede celular (composta por carboidratos, tais como quitina), além de proteínas e lipídios em quantidades significativas do fitopatógeno ou interromper os processos relacionados a sua síntese. Portanto, a produção de enzimas que hidrolisem os componentes da parede celular dos fitopatógenos, particularmente quitinases e glucanases, é uma característica comum em muitos agentes de biocontrole. Algumas representantes do genro Trichoderma são citados em trabalhos como um excelente produtor de celulase e quitinases, enzimas que degradam celulose e quitina (MELO, 1991; HARMAN et al., 2004).

O micoparasitismo, situação em que o microrganismo antagonista vive sobre ou dentro do fungo antagonizado, alimentando-se e desenvolvendo-se às expensas deste, é outro mecanismo de ação importante como atributo de um bom biocontrolador. O micoparasitismo envolve antibiose e canibalismo provocados pela ação de enzimas hidrolíticas, como quitinases, glucanases, proteases e lipases, que provocam a morte de um deles que, assim, servem de alimento para o sobrevivente (LOBO JUNIOR; ABREU, 2000; HARMAN, 2000; BOMFIM, 2007; BARRA et al., 2008; ZUCCHI, 2010).

Quitinases e $\beta$-1,3-glucanases estão diretamente envolvidas nas interações de micoparasitísmo entre espécies de Trichoderma e seus hospedeiros, devido à maioria dos fungos fitopatogênicos possuírem em sua parede celular quitina, organizada em camadas regularmente ordenadas e $\beta$-1,3-glucanas arranjadas como um enchimento de maneira amorfa. A quitinase age de forma aleatória e degradam as estruturas e componentes biológicos das células dos fungos, liberando oligômeros que induzem as exoquitinases, começando assim o ataque micoparasítico, hidrolisando os 
oligossacarideos da parede celular do fitopatógeno. (GIESE et al., 2003; MARCELLO, 2008; BAUERMEISTER et al., 2010).

Melo (1996) relata que micoparasitísmo necrotrófico é eficiente no antagonismo a fitopatógeno, principalmente aqueles com estruturas de resistência consideradas difíceis de serem atacadas por microrganismos, como esporos, escleródios, clamidósporos e microescleródios. Melo; Azevedo (1998) afirma que Trichoderma sp. possui características micoparasítas, pois conseguem localizar e detectar os fitopatógenos, possivelmente por estímulos bioquímicos, crescem em direção hifas de fungos suscetíveis, e ao entrar em contato, formam estruturas como apressórios, enrolam-se, em toda a sua extensão, penetram e os digere. O gênero Trichoderma é sem dúvidas um excelente agente de controle microbiano, pois apresenta além das habilidades descritas acima, características essenciais, sendo elas: impacto ambiental e baixo ou nulo, fácil propagação (SPIEGEL; CHET, 1998), capacidade de sobreviver em ambientes desfavoráveis, além de conter populações de patógenos habitantes do solo (VINALE et al., 2008).

\section{CONSIDERAÇÕES FINAIS}

As relações ecológicas interespecíficas são eventos que ocorrem em diversos níveis na natureza e em sua maioria se faz de formas desarmônicas, na condição de relação entre microrganismos sendo a competição, antibiose e parasitismo as mais frequentes. Desta forma Microrganismos causadores de doença em plantas não só causam perdas econômicas como evoluem de forma simultânea, causando assim danos desde a fase inicial do desenvolvimento da cultura. Métodos tradicionais de controle de fitopatógenos vêm sendo utilizado, a aplicação de pesticidas químicos e fungicidas, tem sido ainda uma forma muito frequente que causam grandes problemas devido aos impactos ambientais.

Uma das maneiras mais promissoras de conseguir uma redução no uso desses agroquímicos, ou até uma futura substituição, controle biológico através dos inúmeros 
biocontroladores como os fungos do gênero Trichoderma que se mostram eficientes e não causam impactos ambientais destrutivos.

\section{REFERÊNCIAS}

AGRIOS, G.N. Plant pathology. Amsterdam : Elsevier Academic Press. 5.ed, 2005. 922p.

ALVES, A., A., C.. Fisiologia da mandioca. In: Aspectos socioeconômicos e agronômicos da mandioca. EMBRAPA Mandioca e Fruticultura Tropical, Cruz das Almas, 2006., 817p.

AMORIM, L.; REZENDE, J. A. M.; BERGAMIN FILHO, A. Manual de Fitopatologia. Piracicaba: Agronômica Ceres. v. 1,4. Ed, p. 383 -387, 2011.

BARBOSA, R.J.F.; MEZA, C.L.S. Antagonismo in vitro de Trichoderma harzianum rifai sobre Fusarium oxysporum schlecht $f$. sp passiflorae en maracuyá (Passiflora edulis sims var. flavicarpa) del municipio zona bananera colombiana. Rev. Fac. Nal. Agr. Medellín, v.62, n.1, p.4743-4748, 2009.

BARRA, V. R.; ROMEIRO, R.S.; FERRAZ, H.G.M.; MACAGNAN, D.; SILVA, H. S. A.; MOURA, A. B.; HALFELD-VIEIRA, B. A; MENDONÇA, H. L.; VIEIRA JÚNIOR, J. R. Potencialidade antagonística em alguns procariotas agentes de biocontrole de enfermidades de plantas. Ver. Summa Phytopathologica, v.34, n.2, p.121-126, 2008.

BAUERMEISTER, A.; REZENDE, M. I.; GIESE, E. C.; DEKKER, R. F. H.; BARBOSA, A. M. 1,3-Glucanases Fúngicas: produção e aplicações biotecnológicas. LONDRINA SP. rev. Semina: Ciências Exatas e Tecnológicas, , v. 31, n. 2, p. 75-86, jul./dez. 2010. http://www.uel.br/seer/index.php/semexatas/article/view/5249

BETTIOL, W. Controle biológico de doencas do filoplano. In: BETTIOL, W., org. Controle biológico de doencas de plantas. Jaguariuna: EMBRAPA-CNPDA, 1991. p.33-52 (EMBRAPA-CNPDA. Documentos, 15). 
BETTIOL, W.: MORANDI, M.A.B. Controle Biológico de Doenças de Plantas no Brasil. In: BETTIOL, W.: MORANDI, M.A.B. (Org). Biocontrole de Doenças de Plantas: uso e perspectivas. Jaguariúna - SP: Embrapa Meio Ambiente, p. 7-14, 2009.

BETTIOL, W.; GHINI, R. Solos Supressivos. In: MICHEREFF,S. J.; ANDRADE, D. E. G. T.; MENEZES, M. (Eds.) Ecologia e Manejo de patógenos radiculares em solos tropicais. Recife:UFRPE, Imprensa Universitária, 2005. cap.6, p. 125-143.

BIZI, R. M., Utilização de fungos no Controle Biológico de Doenças. < http://www.floresta.ufpr.br/alias/pf/public_html/contbio03.html.> Acesso em 16/11/2015.

BOMFIM, M. P., Antagonismo in vitro e in vivo de Trichoderma spp. a Rhizopus stolonifer em maracujazeiro amarelo. Vitória da Conquista BA, 2007. 74f.: Dissertação de Mestrado. Universidade Estadual do Sudoeste da Bahia. 2007

BOMFIM, M. P., SÃO JOSÉ, A. R., REBOUÇAS, T. N. H., ALMEIDA, S. S. D., SOUZA, I. V. B., \& DIAS, N. O . Avaliação antagônica in vitro e in vivo de Trichoderma spp. a Rhizopusstolonifer em maracujazeiro amarelo. Summa Phytopathologyca, v.36, n.1, p. 61-67, 2010.

BRITO, F. S.; MILLER, P. R. M., STADNIK, M. Presença de Trichoderma spp em composto e suas características para o controle de fitopatógenos. Revista. Bras. de Agroecologia, Porto Alegre, p. 43-53. 2010.

CANCELA, K. C., Controle Biológico Florestal Conceitos, Terminologia, Descrição e Caracterização de Agente. Proteção florestal Disponível em $<$ http://www.floresta.ufpr.br/alias/pf/public_html/contbio01.html> Acesso em 16/11/2015.

CARVALHO FILHO, M. R., Relações filogenéticas, identificação e potencial de uso de isolados de Trichoderma no controle do mofo branco e como promotores 
de crescimento do feijoeiro. Brasília-DF, 2013. 123f. Tese de Doutorado. Programa de Pós-graduação em Fitopatologia, Universidade de Brasília. Brasília. 2013.

CARVALHO, A. C., Bioprospecção de isolados de Trichoderma stromaticum para o controle biológico da Vassoura-de-Bruxa do Cacaueiro. 2006. 82f. Dissertação de Mestrado. Universidade Estadual de Santa Cruz. 2006.

CONAB- CLAYDON, N.; ALLAN, M.; ITANSON, J.R.; AVENT, A. G. Antifungal alkyl pyrones of Trichoderma harzianum. Transactions of the British Mycological Society, v.88, p.503-513, 1987. COMPANHIA NACIONAL DE ABASTECIMENTO. Perspectivas para a agropecuária. Conab, Brasília , v.1, 2013., 154p.

DA SILVA, D. C. V., TIAGO, P. V., \& DE SOUZA-MOTTA, C. M. . Isolamento e seleção de fungos filamentosos do solo de sistemas agroflorestais do Município de Bom Jardim (PE) com base na capacidade de produção de enzimas hidrolíticas1. Revista Brasil. Bot, 34(4), 607-610. 2011

DIANESE, A. de C. Variabilidade e controle de Phytophthora palmivora (Podridão-do-pé) e controle da varíola (Aperisporium caricae) do mamoeiro (Carica papaya). 2007. 109f. Tese Doutorado - Universidade de Brasília, Brasília. 2007

DIAS, P. P., Controle biológico de fitopatógenos de solo por meio de isolados de fungos do gênero Trichoderma e sua contribuição no crescimento de plantas. 2011. 101 f. Tese Doutorado. Universidade Federal Rural do Rio de Janeiro. Seropédica - Rio de Janeiro. 2011

DINIZ, M. de S.. Efeito da manipueira na adubação da mandioca. Revista Raízes e Amidos Tropicais, v. 5, 2009.

DOS SANTOS, J. et al. Atividade hiperparasíticade Trichoderma spp. sobre escleródios de Sclerotinia sclerotiorum em solo. In: SEMINÁRIO DE INICIAÇÃO CIENTÍFICA 
TECNOLÓGICA,7,2010.Anais...EPAMIG,2010.Online.Disponívelem:http://www.epa mig.br/index.phpoption=com_docman\&task=cat_view\&gid=121\&dir=DESC\&order=da te\&limit=10\&limitstart=10.Acesso em Dezembro 2015

ETHUR, L.Z. Dinâmica populacional e ação de Trichoderma no controle de fusariose em mudas de tomateiro e pepino. 2006. 154p. Tese (Doutorado em Fitopatologia) - Universidade Federal de Santa Maria, Santa Maria-RS. 2006.

EZZIYYANI, M.; REQUENA, M. E.; EGEA-GILABERT, C.; CANDELA, M. E. Biological Control of Phytophthora Root Rot of Pepper Using Trichoderma harzianum and Streptomyces rochei in Combination. Journal of Phytopathology , [S.I], v.155, n.6, p. 342-349, 2007

FAO. Faostatidtics Database. Disponivel em <https://www.fao.org.br/FAO_Brf2mpu3a.asp> Acesso em Dezembro de 2015.

FIPKE, G. M; PAZINI, J.B.; ETHU,L. Z. Antagonismo de isolados de Trichoderma spp. ao Sclerotinia sclerotiorum em diferentes temperaturas. Magistra, Cruz das Almas BA, V. 27, N.1, p. 23 - 32, Jan./Mar. 2015

FUKUDA C.; OTSUBO A.A. Cultivo da mandioca na região centro sul do Brasil. Embrapa Mandioca e HTTP://sistemasdeproducao.cnptia.embrapa.br/FontesHTML/Mandioca/mandioca_c entrosul/doenc s.htm . Acessado em 16 de julho de 2015.

FRAIFE FILHO G. A., BAHIA J. J. S., Mandioca. Ceplac-Cepec-BA. http://www.ceplac.gov.br/radar/mandioca.htm . Acessado Dezembro de 2015.

GIESE, E. C.; BARBOSA, A. M.; SILVA M.L.C. Glucanases Fúngica: Produção e aplicações das $-1,3$ e $-1,6$ glucanases. Revista Biotecnologia Ciência e Desenvolvimento, Brasília-DF, no 30 , P.97-104.. jan/jun 2003.

GOMES, J. C.; LEAL, E. C., Cultivo da Mandioca para a Região dos Tabuleiros Costeiros. In.: Podridão Radicular. Embrapa Mandioca e Fruticultura. Sistemas de 
Produção, 11. ISSN 1678-8796 Versão eletrônica/Jan/2003. https://sistemasdeproducao.cnptia.embrapa.br/FontesHTML/Mandioca/mandioca_ta bcosteiros/doencas.htm . Acesso 13/12/2015.

HOFFMANN, C. A. et al.. Potencial de antagonismo de isolados de Trichoderma sp. contra o isolados de Fusarium sp., in vitro. Revista Verde de Agroecologia e Desenvolvimento Sustentável, v. 10, n. 1, p. 236-242, 2015.

HARMAN, G. E. The Nature and Application of Biocontrol Microbes II: Trichoderma spp. Overview of Mechanisms and Uses of Trichoderma spp. Phytopathology, St Paul, v. 96, p. 190-194. 2005

HARMAN, G. E. Myth and dogmas of biocontrol changes in perceptions derived from research on Trichoderma harzianum T-22. Plant Disease, St. Paul, v. 84, p.377-393, 2000.

HARMAN, G.E. HOWELL, C. R., VITERBO, A., CHET, I., \& LORITO, M. Trichoderma species-opportunistic, avirulent plant symbionts. Nature Reviews Microbiology. V.2, p. 43-56. 2004.

IBGE - Instituto Brasileiro de Geografia e estatística. PAS - Pesquisa Anual de Serviços, 2015. [online] Disponível na internet via WWW URL: http://www.ibge.gov.br/home/. Arquivo consultado Dezembro de 2015.

LAZAROTTO, M.; BOVOLINI, M. P.; MACIEL, C. G.; MUNIZ, M. F. B. Seleção in vitro de Isolados de Trichoderma spp. com Potencial de Antagonismo a Isolados Patogênicos de Fusarium spp. In: XVI Simpósio De Ensino, Pesquisa E Extensão, Unifra, v. 3, 2012.

LEAL- BERTIOLI, S. C. DE M. O enfoque molecular na sistemática de fungos. Revisão Anual de Patologia de Plantas. V.6. p. 197-230, 1998 
LOBO JÚNIOR, M. e ABREU, M.S. Inibição do crescimento micelial de Sclerotinia sclerotiorum por metabólitos voláteis produzidos por alguns antagonistas em diferentes temperaturas e pH's. Ciência Agrotécnica, Lavras, v.24, p.521-526, 2000.

LOBO JUNIOR, M.; BRANDÃO, R. S.; CORRÊA, C. A.; GÖRGEN, C. A.; CIVARDI, E. A.; OLIVEIRA, P. de. Uso de braquiárias para o manejo de doenças causadas por patógenos habitantes do solo.Santo Antônio de Goiás: Embrapa Arroz e Feijão, 2009. 8 p. (Embrapa Arroz e Feijão. Comunicado técnico, 183).

MACHADO, D. F. M.; PARZIANELLO, F. R.; SILVA, A. C.F. e ANTONIOLLI, Z. I. Trichoderma no Brasil: o fungo e o bioagente. Revista de Ciências Agrárias, v.35, n.1, p. 274-288, 2012.

MARCELLO, C. M. Avaliação da expressão e caracterização de uma exo-b-1,3glucanase envolvida no mecanismo de micoparasitismo de Trichoderma asperellum. Brasília-DF, 2008. 89f. Tese de Doutorado. Laboratório de Enzimologia Departamento de Biologia Celular do Instituto de Biologia da Universidade de Brasília - UnB. Brasília - DF. 2008.

MARQUES, H. I. P.; SILVA, M. B.; MARQUES, M. D. P.; RODRIGUES, R. C.; RIBEIRO, P. R. C. C. Inibição do crescimento micelial de Trichoderma harzianum por fertilizantes líquidos. Enciclopédia Biosfera, v. 10, n. 18, p. 2040, 2014.

MARTINS, M. K.. Variabilidade genética de isolados de Fusarium spp. e estudo da interação com a planta hospedeira. 2005. 110f. Diss. Tese (Doutorado em Agronomia)-Escola Superior de Agricultura" Luiz de Queiroz", Universidade de São Paulo, SP.[Links], 2005

MASSOLA JR, N.S.; BEDENDO, I. P.. Doenças da mandioca. In: KIMATI, H. et al. Manual de fitopatologia: Doenças das plantas cultivadas;. 4⿳亠丷厂 Ed.vol. 2, p. 340-341 São Paulo: Agronômica Ceres, 2005 
MELO, I. S. Potencialidades da utilização de Trichoderma spp. no controle biológico de doenças de plantas. In: BETTIOL, W. (Ed.). Controle biológico de doenças de plantas. Jaguariúna: CNPDA/EMBRAPA, 1991. p. 135-156.

MELO, I. S.; AZEVEDO, J. L. Ecologia Microbiana. Jaguariúna: Embrapa DNPMA, p. 393-419, 1998.

MELO, I.S. Trichoderma e Gliocladium como bioprotetores de plantas. Revis. Anu. Patol. Plantas v. 4, p. 261-295. 1996.

MENEZES, J. P., LUPATINI, M., ANTONIOLLI, Z. I., BLUME, E., JUNGES, E., \& MANZONI, C. G. Variabilidade genética na região its do rDNA de isolados de trichoderma spp.(Biocontrolador) e Fusarium oxysporum f. sp. Chrysanthemi. Ciência e Agrotecnologia, 34(1), 132-139.2010

MICHEREFF, S.J.; MENEZES, M.; MARIANO, R.L.R. Potencial de Trichoderma para o controle da antracnose do sorgo. Fitopatologia Brasileira, Brasília, v. 18, p. 392-398, 1993.

MILANESI, P.M. Caracterização, toxicidade e patogenicidade de Fusarium spp. em genótipos de soja em sistema plantio direto. 2009. 91 p. Dissertação (Mestrado em Agronomia) - Universidade Federal de Santa Maria, Santa Maria, 2009.

MORAES, W. B. C. Controle alternativo de fitopatógenos. Pesquisa Agropecuária Brasileira, v. 27, n. 13, p. 175-190, 1992.

MORAIS, M. dos S.; NASCIMENTO, L. C do; MOREIRA, K. A.; SILVA, M. da; CAVALCANTI, N. T. D. O. Levantamento e avaliação da incidência das doenças da mandioca no estado da Paraíba. Summa Phytopathologica, v. 39, n. 3, p. 204. 2013.

MOURA, G. de M.; SILVA, M. D. O. da. Avaliação de resistência de cultivares de mandioca à podridão de raízes. Embrapa-CPAF/AC. Comunicado Técnico, 4p. Rio Branco 1997. 
MUNIZ J. N, RUFFINO-NETTO A, YAMAMURA M, VILLA TCS, ARCENCIO R. Aspectos epidemiológicos da coinfecção tuberculose e vírus da imunodeficiência humana em Ribeirão Preto (SP), de 1998 a 2003. J. Bras. Pneumol., 32(6):529-34, 2006

NASCIMENTO JÚNIOR, N. A. Efeito da casca de mandioca no controle da podridão radicular causada por Phytophthora sp. em mandioca de mesa (Manihot esculenta Crantz) var. Rosinha em ambiente irrigado. Rio LargoAL,2015.82f. Tese de Doutorado. (Programa de Pós-Graduação em Proteção de Plantas da Universidade Federal de Alagoas. Alagoas. 2015.

NOTARO, K. A. MEDEIROS, E. V., SILVA, C. A. D., \& Barros, J. A. Prospecção de fitopatógenos associados á podridão radicular da mandioca em Pernambuco, Brasil. Biosci. J., Uberlândia, v. 29, n. 5, p. 1832-1839, 2013.

NOTARO, K. A. Prospecção de fitopatógenos e caracterização de solos arenosos envolvidos na supressividade ou conducividade da podridão radicular da mandioca, causada por Neoscytalidium lignicola/ Krystal de Alcantara Notaro. Garanhuns-PE, 2012. 111f. Dissertação (PROGRAMA DE PÓS-GRADUAÇÃO EM PRODUÇÃO AGRÍCOLA). Universidade Federal Rural de Pernambuco - Unidade Acadêmica de Garanhuns, 2012.

O`DONNELL, K.; NIRENBERG, H.I.; AOKI, T.; CIGELNIK, E. A multigene phylogeny of the Gibberella fujikoroi species complex: detection of additional phylogenetically distinct species.Mycoscience, Tokyo, v. 41, p. 61-78, 2000.

OLIVEIRA, L. G. SILVA, A.C.S; SILVA, R. L. ,LIMA, D. W. S \& LIMA, G; COSTA. Atividade proteolítica de fungos de solo fitopatogênicos ao Feijão-Caupi [Vigna unguiculata (L.) Walp.] In: III CONAC Congresso Nacional de Feijão-Caupi. Pernambuco. Resumo expandido. 4p. 22-24 de abril Recife Pernambuco 2013.

OLIVEIRA, N. T; J. M. A., UCHÔA, S. C. P., RODRIGUES, G. S., MELVILLE, C. C., \& de ALBUQUERQUE, J. D. A. A.. Caracterização e identificação de clones de 
mandioca produzidas em Roraima para o consumo in natura. Revista Agro@mbiente On-line, v. 5, n. 3, p. 188-193, 2012.

OTTONI, R.J. Analise da incidência de Fusarium spp. toxigenicos e de níveis de fumonisinas em grãos ardidos de milho hibrido. 2008. 54 p. Dissertação (Mestrado em Microbiologia Agrícola) - Escola Superior de Agricultura "Luiz de Queiroz", Universidade de São Paulo, Piracicaba, 2008.

PEREIRA, C O.F. Estudo da patogenicidade e controle biológico de Fusarium sp. Com Trichoderma sp. 2013.74f. Dissertação. Universidade de Caxias do Sul. 2013.

PUHALLA, J.E. Genetic considerations of the genus Fusarium. In: Nelson, P.E.; Toussoun, T.A.; Cook, R.J. (Ed) Fusarium: diseases, biology, and taxonomy. Pennsylvania: Pennsylvania State University, v.27, p.291-305, 1981.

QUERALES, P. J.. Caracterização morfológica e genética de Fusarium spp. isolados de sementes e associados à podridão do colmo de milho (Zea mays L.). Diss. Escola Superior de Agricultura "Luiz de Queiroz, 2010.

REMUSKA, A.C.; DELLA PRIA, M. Efeito de Bacillus truringiensis e Trichoderma sp. no crescimento de fungos fitopatogênicos. Publication UEPG: Ciências Exatas e da Terra, Agrárias e Engenharia, Ponta Grossa, v.13, n.3, p.31-36, 2007.

ROBBS, F. C. Controle Biológico de doenças em plantas. In: NETO, A. M. A.; BARAN, C. L. (ed.). Manual de Controle Biológico. Rio de Janeiro: Lidador. 1992. p.4651.

ROLLAN, MONACO C, NICO A. Efecto de la tempratura sobre la interaccion invitr o entre especies de Tricihoderma y Sclerotinia sclerotiorum, S. minor y Sclerotium rolfsii. Invest. Agr.: Prod. Prot. Veg. 14:1-16. 1999.

RONDÓN T.R, GUTIÉRREZ GR, ZAYAS A.D.P, PÉREZ LA, CUTIÑO Y.L. Efectividad in vitro de Trichoderma harzianum Rifai para el biocontrol de 
Rhizoctonia solani Kühn y Pyricularia Grisea sacc. aislados en el cultivo del arroz (Oryza sativa I.). Fitosanidad 11: 29-34.2007.

SALLA, D. A., CABELLO, C. Análise energética de sistemas de produção de etanol de mandioca, cana-de-açúcar e milho. Revista Energia na Agricultura. Botucatu, vol. 25, n.2, p.32-53., 2010.

SANTOS, C. C., OLIVEIRA, F. A. de; SANTOS, M. S. dos; TALAMINI, V.; FERREIRA, J. M. S.; SANTOS, F. J. dos., Influência de Trichoderma spp. sobre o crescimento micelial de Thielaviopsis paradoxa. Scientia Plena 8, 047309 www.scientiaplena.org.br. 2012

SEIFERT, K.A. Enhancing the relevance of fungal taxonomy to plant pathology: phylogenetics, molecular diagnostics, and long-term memory1. Symposium contribution. Canadian Journal of Plant Pathology, Otawa, v. 28, p. S280-S287, 2006 .

SILVA, A. N.; AZEVEDO, G. B.; ROCHA-SOBRINHO, G. G.; NOVAES, Q. S.; Efeito de produtos químicos e de Trichoderma spp. no controle de Fusarium solani do maracujazeiro. Interciencia, v. 6, p. 398-403, 2014.

SILVA, C. A. D., DE MEDEIROS, E. V., BEZERRA, C. B., DE MORAIS; SILVA, W., DE BARROS, J. A., \& DOS SANTOS, U. J. Interferência da incorporação de matéria orgânica no solo no controle da podridão negra da mandioca, causada por Scytalidium lignicola. Biosci. J., Uberlândia, v. 29, n. 6 , p. 1823-1831, Nov./Dec. 2013.

SILVA, C. A. D., Prospecção em fitopatógenicos e avaliação de fontes de matéria orgânica sobre a supressividade da podridão radicular da mandioca. GaranhunsPE, 2013. 77 f. Dissertação (Mestrado em Produção Agrícola). Universidade Federal Rural de Pernambuco - Unidade Acadêmica de Garanhuns, 2013. 
SILVA, H. S. A.; ANDRADE, E. C. Impacto potencial das mudanças climáticas sobre as doenças da mandioca no Brasil. In: Impactos das mudanças climáticas sobre doenças de importantes culturas no Brasil. Jaguariúna: Embrapa Meio Ambiente, p. 263-272, 2011.

SILVA, J. L.; TEIXEIRA, R. N. V. Esporulação e crescimento micelial de Fusarium solani em diferentes meios de cultura e regimes de luminosidade. Revista Agrombiente On-line,v.6,n.1,p.47-52, 2012. Disponível em: <http://revista.ufrr.br/index.php/agroambiente/article/view/604>

SILVA, K. S.; REBOUÇAS, T. N. H.; BOMFIM, M. P.; SILVA, D. S.; SÃO JOSÉ, A. R.; BENETT, C. G. S. Atividade antagônica in vitro de isolados de Trichoderma spp. ao fungo Phytophthora citrophthora. Londrina. Semina: Ciências Agrárias, v. 29, n. 4, p. 749-754, out./dez. 2008.

SILVA, M.B.; NICOLI, A. COSTA, A.S.V.; BRASILEIRO, B.G.; JAMAL, C.M., SILVA, C. A.; PAULA JÚNIOR, T. J.; TEIXEIRA, H. Ação antimicrobiana de extratos de plantas medicinais sobre espécies fitopatogênicas de fungos do gênero Colletotrichum. Revista Brasileira de Plantas Medicinais, Botucatu, v.10, n.3, p.5760, 2008.

SOUSA, R.M.S.; SERRA, I.M.R.S.; MELO, T.A. Effect of essential oils as an alternative in the control of Colletotrichum gloesporioides in pepper.Summa Phytopathologica , v.38, n.1, p.42-47, 2012.

SOUZA, J. R., Potencialidade de fungicida e agente biológico no controle de requeima do tomateiro. 2013. 63f. Dissertação. Universidade Estadual do Sudoeste da Bahia, Vitória da Conquista. Bahia - BR. 2013.

SOUZA, K. de A.;VAZ, M. C. A.; ALVES, G. C. S.; PAZ -LIMA, M. L.. Confronto in vitro de isolados de Trichoderma spp. com fungos filamentosos. $2 p$. IV Congresso Estadual de Iniciação Científica do IF Goiano 21 a 24 de setembro de 2015. 
SPIEGEL, Y.; CHET, I. Evolution of Trichoderma spp. as a biocontrol agent against soilborne fungi and plant parasitic nematodes in Israel. Integrated Pest Management Review, v. 03, p. 167-175, 1998.

STANGARLIN, J.R. et al. Controle de doenças de plantas por extratos de origem vegetal. Revisão Anual de Patologia de Plantas, v.16, p.265-304, 2008.

URBEN, A.F., et al., Curso taxonomia de Fusarium. Embrapa recursos genéticos e biotecnologia. Brasilia-DF: Embrapa informação tecnólogica, 2009.

VENTURA, J. A. Taxonomia de Fusarium e seus segregados: I- história, meios e procedimentos de cultivo. Revisão Anual de Patologia de Plantas , Passo Fundo, v. 7, p. 271-298, 1999.

VINALE F, SIVASITHAMPARAM, K., GHISALBERTI, E. L., MARRA, R., WOO, S. L., \& LORITO, M.. Trichoderma-plant-pathogen interactions. Soil Biology and Biochemistry, v. 40, p.1-10.2008.

ZUCCHI, F. O. Trichoderma sp. em áreas agrícolas visando o controle de doenças fúngicas de raízes de plantas cultivadas. Campinas SP. JV Biotecnologia. 15p. 2010.

\section{APÊNDICE - REFERÊNCIA DE NOTA DE RODAPÉ}

1. WOLLENWEBER, H. W.; REINKING, O. A.. Die fusarien: ihre beschreibung, schadwirkung und bekämpfung. Berlin: P. Parey, 1935

Enviado: Maio, 2020.

Aprovado: Junho, 2020. 